|IIIIIIIIIIIIIIIIIIIIIIIIIIIIIIIIII

Original Article

IIIIIIIIIIIIIIIIIIIIIIIIIIIIIIIIII

\title{
Phylogenetic diversity and sensitivity to MBI and QoI fungicides of Magnaporthe oryzae in Taiwan
}

\author{
Chien-Hsiang Hsien, ${ }^{1}$ Wen-Chuan Chung, ${ }^{2}$ Yi-Nian Chen $^{3}$ and Wen-Hsin Chung ${ }^{1, *}$ \\ ${ }^{1}$ Department of Plant Pathology, National Chung Hsing University, Taichung 40227, Taiwan \\ ${ }^{2}$ Taiwan Seed Improvement and Propagation Station, Hsinshe, Taichung 426, Taiwan \\ ${ }^{3}$ Plant Pathology Division, Taiwan Agricultural Research Institute, COA, Taichung 41362, Taiwan
}

(Received October 2, 2012; Accepted August 16, 2013)

\begin{abstract}
Magnaporthe oryzae (Anamorph: Pyricularia oryzae), the causal agent of rice blast disease, is the major pathogen that reduces the yield of rice worldwide. Melanin biosynthesis inhibitors (MBIs) and strobilurins (QoIs) are common fungicides used to control the disease. One hundred and three M. oryzae isolates from different rice-production areas in Taiwan were evaluated for their molecular phylogeny and sensitivity to MBI and QoI fungicides. Molecular phylogenetic analysis showed that all M. oryzae isolates could be classified into nine genetic groups (A-I) based on the DNA polymorphism amplified by CNS1/MP primers. Predominant ones are groups A (72 isolates) and B (15 isolates). Fungicide tests showed that $M$. oryzae isolates were sensitive to MBIs (carpropamid and tricyclazole) and less sensitive to QoIs (kresoxim-methyl and azoxystrobin). Amplifying the cytochrome $b$ (cyt $b$ ) gene revealed that isolates with low sensitivity to QoIs did not correspond with mutation at codon 129 or 143 in the cyt $b$ gene. (c) Pesticide Science Society of Japan
\end{abstract}

Keywords: Molecular phylogeny, MBIs, QoIs, cytochrome $b$ (cyt $b$ ) gene.

\section{Introduction}

Rice blast caused by Magnaporthe oryzae (Hebert) Barr. (Anamorph: Pyricularia oryzae Cavara.) is an important disease in rice-production areas worldwide. ${ }^{1)}$ This disease reduces yield by $10-30 \%$ worldwide. ${ }^{2)}$ Previous studies indicated that the pathogenicity of $M$. oryzae varies greatly in nature. ${ }^{3,4)}$ Recent studies also showed that pathogenicity of $P$. oryzae to different rice cultivars or lines differs in different countries, including Argentina, ${ }^{5)}$ Brazil, ${ }^{6-8)}$ China, ${ }^{9)}$ USA, ${ }^{10)}$ Thailand, ${ }^{11)}$ and Vietnam. ${ }^{12)}$ In Taiwan, more than 78 races of $P$. oryzae had been identified using 8 standard lines of rice as differentials. ${ }^{13)}$ However, pathotype or race identification of $P$. oryzae by artificial inoculation is easily affected by environment and rice cultivar. ${ }^{14)}$ Therefore, molecular markers were applied to study the population structure of $P$. oryzae in the field, ${ }^{15)}$ including MGR (Magnaporthe grisea repeat element), ${ }^{10,16)}$ MAGGY (M. gypsy-like element), ${ }^{17,18)}$ Pot2 (P. oryzae repeat 2$)^{19)}$ and SSR (simple sequence repeat). ${ }^{20)}$

Many fungicides, including acid amides, aliphatic compounds, organo-phosphorus compounds, antibiotics, benzimidazoles, strobilurins, organo-sulphur compounds and het-

\footnotetext{
* To whom correspondence should be addressed.

E-mail: wenchung@nchu.edu.tw

Published online October 29, 2013

(c) Pesticide Science Society of Japan
}

erocyclic compounds, are recommended for controlling rice blast. ${ }^{21,22)}$ Among these compounds, carpropamid of acid amides and tricyclazole of heterocyclic compounds are the most commonly used fungicides in Taiwan. ${ }^{22}$ Based on the guidelines published by the Fungicides Resistance Action Committee (FRAC), the melanin biosynthesis inhibitors (MBIs) belonging to Code I could be separated into two groups based on their target enzyme: reductase inhibitors (MBI-R) that include tricyclazole and dehydratase inhibitors (MBI-D) that include carpropamid. ${ }^{23)}$ Recent studies indicated that carpropamidresistant isolates of $M$. oryzae had been detected in Japan. ${ }^{24-27)}$ Moreover, certain reports indicated that the decreased efficacy of carpropamid against rice blast in Saga Prefecture in Japan was due to point mutation at codon 75 (GTG $\rightarrow$ ATG) in the scytalone dehydratase $(S D H)$ gene and the amino acid valine changing into methionine. ${ }^{24,25)}$ However, the tricyclazole-resistant isolate still could not be detected in a natural field and the mechanism of tricyclazole resistance generated by UV radiation is still not clear. $^{28)}$

Strobilurins are new fungicides that can inhibit electron transference of cytochrome $b$ to $c$ at complex III in mitochondria. ${ }^{2329)}$ Two strobilurin fungicides, azoxystrobin and metominostrobin, were used to control rice blast in Japan. ${ }^{21)}$ Moreover, azoxystrobin and trifloxystrobin were used to control ryegrass disease caused by $P$. grisea, however, the two strobilurin fungicides lost its efficacy in controlling $P$. grisea. ${ }^{30)}$ In Taiwan, strobilurin fungicides are commonly used for controlling powdery 
or downy mildew of cucumber, downy mildew of crucifer, late blight of tomato and potato, rust disease of allium, anthracnose of fruits and other fungal diseases of fruits. ${ }^{22)}$ Previous studies demonstrated that the isolates of Botrytis cinerea from strawberry and Colletotrichum gloeosporioides from mango and strawberry showed low sensitivity to kresoxim-methyl, azoxystrobin and triflorstrobin. ${ }^{31,32)}$ Presently, more than 36 fungal pathogens have been reported to show resistance to strobilurins. ${ }^{23)}$ The studies of strobilurin resistance in fungal pathogens indicated that mutation in the cytochrome $b$ (cyt $b$ ) gene is the major mechanism for generating resistance. ${ }^{33,34)}$ The mutation at codon 129 (TTC $\rightarrow$ TTA) is associated with moderate resistance, and mutation at codon 143 (GGT $\rightarrow \mathrm{GCT})$ is associated with resistance. $^{34)}$

In Taiwan, rice blast is endemic to the first rice cultivation (March to June), affecting over 20,000 ha each year. ${ }^{35)}$ Previous studies showed the presence of more than 20 races of $M$. oryzae by the standard lines of rice. ${ }^{13)}$ However, changes in the population structure of $M$. oryzae are unknown in past 20 years. The objectives of this study were (1) to determine the molecular diversity of $M$. oryzae from different production areas in Taiwan, (2) to test the sensitivity of M. oryzae isolates to MBI fungicides (carpropamid and tricyclazole) and strobilurin fungicides (kresoxim-methyl and azoxystrobin), and (3) to further analyze cross-resistance between $M$. oryzae isolates.

\section{Materials and Methods}

\section{Fungal isolates and fungicides}

A total of 103 isolates of $M$. oryzae originally isolated from diseased plants were used in this study (Table 1). All cultures were derived from single conidia and maintained at $4^{\circ} \mathrm{C}$ on potato dextrose agar (PDA) (Difco, Detroit, USA). The melanin synthesis inhibitors (MBIs) [tricyclazole (75\% WP, Elanco) and carpropamid (15\% SC, Bayer)] and strobilurin fungicides [kresoxim-methyl (44.2\% SC, BASF) and azoxystrobin (10\% SC, Syngenta)] were used to evaluate their efficacy as growth inhibitors of M. grisea.

\section{DNA extraction}

The biomass for each isolate was collected from $50 \mathrm{~mL}$ of a potato dextrose broth (PDB) culture incubated at $24^{\circ} \mathrm{C}$ for 10 days. Mycelia were harvested through two layers of sterilized cheesecloth, rinsed with sterile water and stored at $-80^{\circ} \mathrm{C}$ until being lyophilized. Total DNA of mycelial mats for each isolate was extracted with a sodium dodecylsulfate (SDS) detergent lysis buffer followed by phenol/chloroform extraction and precipitation in ethanol with sodium acetate. ${ }^{36)}$ All DNA extracts were adjusted to a final concentration of $20 \mathrm{ng} / \mu \mathrm{L}$ and $1-2 \mu \mathrm{L}$ of the extract was used for each PCR.

\section{Molecular phylogenetic analysis of M. oryzae}

Abd-Elsalam et al. (2009) indicated that a combination of intergenic spacer (IGS) rDNA and microsatellite-primed polymerase chain reaction (MP-PCR) primers could identify the intra-species of Rhizoctonia solani. ${ }^{15)}$ In this study, primers CNS1 (5'-GAGACAAGCATATGACTACTG-3') and MP (5'-CAGCAGCAGCAGCAG-3') were used to amplify the DNA fragment. The PCR conditions were as follows: initial denaturation at $94^{\circ} \mathrm{C}$ for $2 \mathrm{~min}, 40$ cycles at $94^{\circ} \mathrm{C}$ for $1 \mathrm{~min}, 52^{\circ} \mathrm{C}$ for $1.5 \mathrm{~min}, 72^{\circ} \mathrm{C}$ for $2 \mathrm{~min}$, and final extension at $72^{\circ} \mathrm{C}$ for $7 \mathrm{~min}$. Amplifications of the total DNA were conducted using $25 \mu \mathrm{L}$ of PCR reaction mixtures, each containing $0.2 \mu \mathrm{M}$ of each primer, 1 unit of Taq DNA polymerase (GeneMark, Taichung, Taiwan), and a dNTP mixture (containing $250 \mu \mathrm{M}$ of each dNTP), and a Taq reaction buffer (containing $2 \mathrm{mM} \mathrm{MgCl}_{2}$ ). PCR products separated in $2 \%(\mathrm{w} / \mathrm{v})$ agarose gels containing $0.5 \mu \mathrm{g} / \mathrm{mL}$ of ethidium bromide in TAE (Tris-acetate, EDTA) buffers. The results were analyzed by the neighbor-joining method of MEGA4

Table 1. Isolates of Magnaporthe oryzae obtained from different rice production areas in Taiwan

\begin{tabular}{|c|c|c|c|}
\hline Location & Isolate & Genetic group & No ${ }^{a)}$ \\
\hline Maioli & $\begin{array}{l}\text { YL1004 a-1, YL1004 a-2, YL1004 a-3, TG9-01, TG9-02, TNoN73-02, TG16-02, KS139-01, MTC192-01, } \\
\text { MTC192-02 }\end{array}$ & $A, B, D$ & 10 \\
\hline Taichung & $\begin{array}{l}\text { WF1004 b-1, WF1004 b-2, WF1004 b-3, WF1004 a-1,WF1004 a-2, WF1004 a-3, TNa11-03, TG2-03, } \\
\text { NGT, WFTG9-01, WFTG9-02, WFTNa11-01, WFTNa11-02, WFTC186-01, WFTC186-02, } \\
\text { WFTN70-01, WFTN70-02 }\end{array}$ & A, B & 17 \\
\hline Changhua & ST-1003 a-1, ST-1003 a-2, ST-1003 a-3 & A, B & 3 \\
\hline Yunlin & XK-1003 a-1, XK-1003 a-2, XK-1003 a-3, YL-1003a-1, YL-100 3 a-2, YL-1003 a-3, TK-01, TK-02 & $A, B, C$ & 8 \\
\hline Chaiyi & $\begin{array}{l}\text { TNoN73-01, KS139-01, KS139-02, TG16-01, TNo71-01, TNo71-02, TG4-01, TG4-02, TG2-01, TG2-02, } \\
\text { TG8-01, TG8-02, TG5-01, TG5-02,TT30-01,TT30-02, TNa11-01, TNa11-02, TNo74-01, KS145-01, } \\
\text { KS145-02, TNo67-01, TNo67-02, TY3-01, TY3-02, TG9-01, TG9-02, TTN31-01, TTN31-02, TGN3-01, } \\
\text { TGN3-02, TC193-01, TC193-02, HL21-01, SG-01, Lomello01, LC-01 }\end{array}$ & $\begin{array}{l}\text { A, B, C, D, E, } \\
\quad \text { F, G, H, I }\end{array}$ & 37 \\
\hline Tainan & HB-01, HB11, Hb-1003 a-1, Hb-1003 a-2, Hb-1003 a-3, Hb-1003 b-1, Hb-1003 b-2, Hb-1003 b-3 & A, C & 8 \\
\hline Kaohsiung & MN-1003 a-1, MN-1003 a-2, MN-1003 a-3, MN-1003 b-1, MN-1003 b-2, MN-1003 b-3 & A, B & 6 \\
\hline Pingtung & $\begin{array}{l}\text { PT-31003 a-1, PT-3 } 1003 \text { a-2, PT-3 } 1003 \text { a-3, PT-1003 b-1, PT-1003 b-2, PT-1003 b-3, XY-1003 a-1, } \\
\quad \text { XY-1003 a-2, XY-1003 a-3, XY-1003 b-1, XY-1003 b-2, XY-1003 b-3, ChJ-01, PD-01 }\end{array}$ & A, B & 14 \\
\hline Total & & & 103 \\
\hline
\end{tabular}

a) Number of isolates from different area. 
(Oxford University Press, Ltd., UK) to construct the molecular phylogeny of $M$. oryzae isolates.

\section{Sensitivity to MBIs and strobilurin fungicides}

The sensitive estimation of $M$. oryzae isolates to MBI fungicides was performed following the method reported by Eizuka et al. (2001) for observing the melanization of appressoria. ${ }^{37)}$ The $10 \mu \mathrm{L}$ of $10^{5}$ conidia/mL suspension of $M$. oryzae was loaded on the $10-\mathrm{mm}$ squares of cellulose membranes (Membrane Filtration Products, Inc., Texas, USA) immersed in sterilized filter paper (Advantec Toyo No. 2, $70 \mathrm{~mm}$ in diameter) with tricyclazole and carpropamid. The fully melanized or unmelanized $M$. oryzae mycelia were evaluated by light microscope after 2 days of culture at $25^{\circ} \mathrm{C}$ in the dark. The determination of minimum inhibitory concentration (MIC) of tricyclazole and carpropamid was followed by the appressorial unmelanization at the lowest concentration. ${ }^{37)}$ The concentrations of two MBI fungicides tested in this study were $0.01,0.10,0.20,0.40,0.60,0.80$, $1.0,1.5,2.0,3.0$ and $4.0 \mu \mathrm{g}$ of the active ingredient (a.i.) $/ \mathrm{mL}$.

Sensitivity to strobilurin fungicides was determined by mycelial growth assays. Each isolate was cultured on PDA in petri dishes at $20^{\circ} \mathrm{C}$ for 7 days. Mycelial disks $(0.3 \mathrm{~cm}$ in diameter) were cut from colony margins and single disks transferred to the center of PDA dishes amended with $0,1,10,100$ or $500 \mu \mathrm{g}$ a.i./mL of each of the two MBI fungicides or two strobilurin fungicides. Fungicides were added to PDA after autoclaving. After incubation in darkness at $20^{\circ} \mathrm{C}$ for 5 days, colony diameters were measured, and the effective concentration for $50 \%$ inhibition $\left(\mathrm{EC}_{50}\right)$ was calculated using Probit-MSChart, provided by Prof. Chi. There were four replicates for each treatment. The experiment was repeated twice.

\section{Analysis of the cytochrome b gene}

The PCR reaction mixture contained $1.5 \mu \mathrm{L}$ total fungal ge-

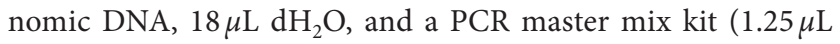
polymerase; $1.25 \mu \mathrm{L}$ reaction buffer; $1.25 \mu \mathrm{L} 1.75 \mathrm{mM} \mathrm{CaCl}_{2}$; $1.25 \mu \mathrm{L} 200 \mu \mathrm{M}$ dNTP) (GeneMark, Taiwan). For cyt $b$ gene amplification, the primer pair Pgcytb_F1/Pgcytb_R1 (5'-AGT CCT AGT GTA ATG GAA GC-3'/5' - ATC TTC AAC GTG TTT AGC ACC- $3^{\prime}$ ) was used. ${ }^{34)}$ The PCR reaction program of the cyt $b$ gene was as follows: $95^{\circ} \mathrm{C}$ for $10 \mathrm{~min} ; 35$ cycles at $94^{\circ} \mathrm{C}$ for $0.5 \mathrm{~min}, 50^{\circ} \mathrm{C}$ for $0.5 \mathrm{~min}$, and $72^{\circ} \mathrm{C}$ for $2 \mathrm{~min}$; and $72^{\circ} \mathrm{C}$ for $5 \mathrm{~min}$. The PCR products were run on $1.5 \%$ agarose gels containing $0.5 \mathrm{~g} / \mathrm{mL}$ ethidium bromide in TAE buffers. PCR products were purified by spin columns (PCR CleanUp Kit, GeneMark) and DNA sequencing was performed on ABI PRISM 3100 automated sequencers (Applied Biosystems, Ramsey Inc., USA). The sequences of $M$. oryzae isolates were blasted with the GenBank of NCBI/DDBJ/EBML to confirm the isolates and analyze the variation of nucleotides.

\section{Results}

1. Molecular phylogenetic analysis of M. oryzae

DNA polymorphisms of $M$. oryzae isolates were classified into

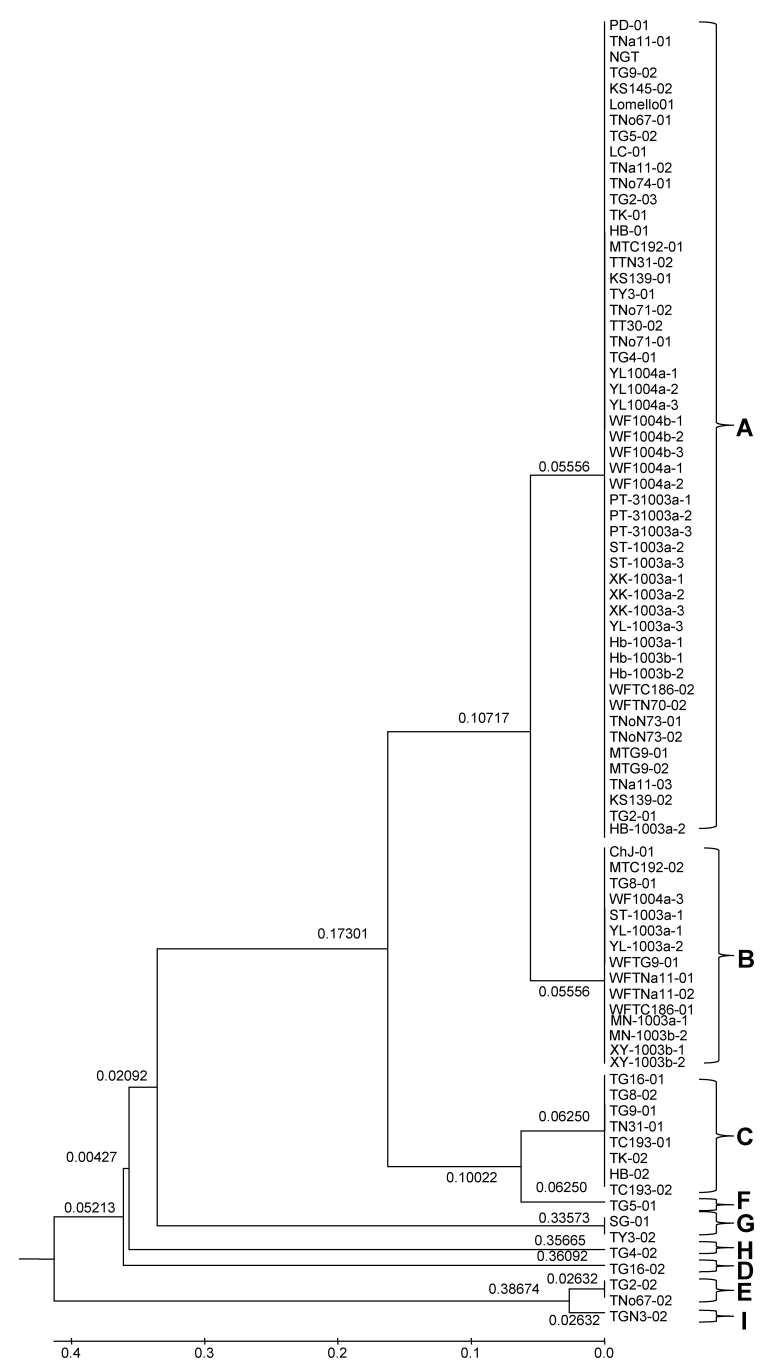

Fig. 1. An IGS-MP-PCR phylogenetic tree generated by MEGA 4 software with neighbor-joining analysis. Values on the branches of the groups represent results of bootstrap analysis with 1000 replications.

nine genetic groups (A-I) based on neighbor-joining analysis (Fig. 1). Among the isolates, 72 were included in group A, 15 in group $\mathrm{B}$ and 8 in group C. Thus, the isolates in groups A, B and $\mathrm{C}$ are considered dominant populations in Taiwan.

\section{Sensitivity to MBIs and strobilurins}

The minimum inhibitory concentration of appressorial melanization (MICAM) values for all isolates was tested in variation between tricyclazole and carpropamid fungicides. The major MICAM values of tricyclazole were distributed from 0.1 to $0.4 \mu \mathrm{g}$ a.i. $/ \mathrm{mL}$ and the numbers of $M$. oryzae isolates at $0.1,0.2$ and $0.4 \mu \mathrm{g}$ a.i./mL (Fig. 2). The major MICAM values of carpropamid were located in 0.6 and $0.8 \mu \mathrm{g}$ a.i. $/ \mathrm{mL}$, and 23 isolates and 42 isolates of $M$. oryzae were located at these two concentrations (Fig. 3).

For the strobilurin sensitivity test, most $M$. oryzae isolates showed low sensitivity to kresoxim-methyl. The $\mathrm{EC}_{50}$ values of kresoxim-methyl against $M$. oryzae were 1 to $10 \mu \mathrm{g}$ a.i. $/ \mathrm{mL}$ for 3 


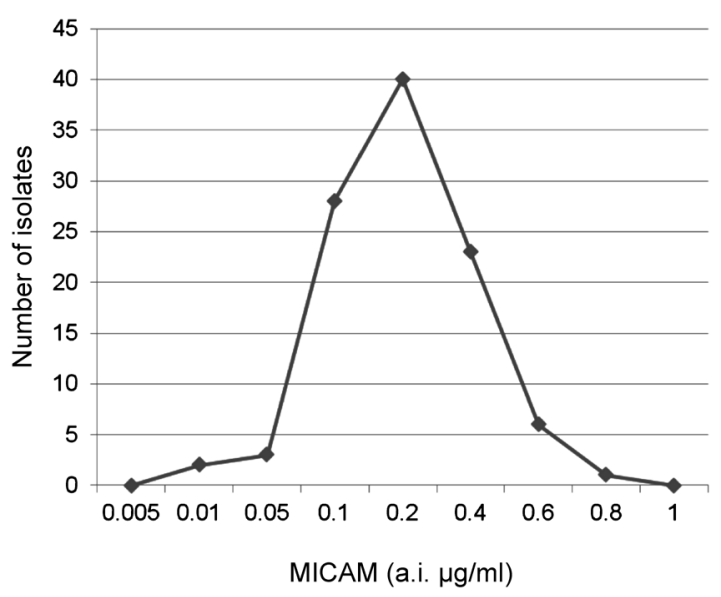

Fig. 2. The distribution of minimum inhibitory concentration of appressorial melanization of Magnaporthe oryzae isolates to tricyclazole.

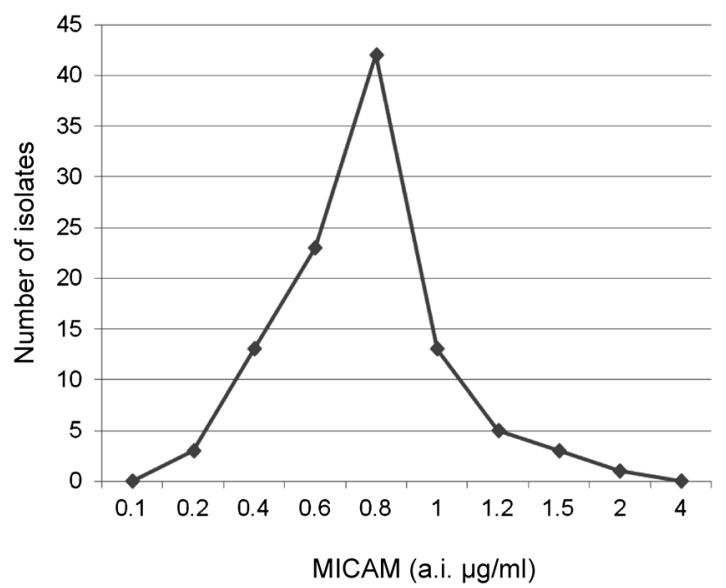

Fig. 3. The distribution of minimum inhibitory concentration of appressorial melanization of Magnaporthe oryzae isolates to campropamid.

isolates, 10 to $100 \mu \mathrm{g}$ a.i./mL for 7 isolates, 100 to $500 \mu \mathrm{g}$ a.i. $/ \mathrm{mL}$ for 15 isolates and $>500 \mu \mathrm{g}$ a.i./mL for 78 isolates (Fig. 4). However, azoxystrobin was more potent in the inhibition of the mycelial growth of $M$. oryzae isolates. The $\mathrm{EC}_{50}$ values of azoxystrobin against $M$. oryzae were $\leqq 1 \mu \mathrm{g}$ a.i./mL for 1 isolate, 1 to $10 \mu \mathrm{g}$ a.i./mL for 20 isolates, 10 to $100 \mu \mathrm{g}$ a.i./mL for 82 isolates and $>500 \mu \mathrm{g}$ a.i./mL for 1 isolate (Fig. 4).

\section{Analysis of the cytochrome b (cyt b) gene at codons 129 and 143}

Mutation at codon 129 or 143 had been demonstrated to associate with moderate resistance or resistance to strobilurin fungicides. $^{34)}$ DNA of 50 isolates of $M$. oryzae expressing various levels of sensitivity to kresoxim-methyl and azoxystrobin were sequenced and evaluated for mutations at codons 129 and 143 of the cyt $b$ gene. The results showed that all isolates having sensitivity or low sensitivity to the strobilurin fungicides had the wild-type sequence of TTC (Phe) and GGT (Gly) at codons 129 and 143. Partial sequences of the cyt $b$ genes that included codons 129 and 143 of the M. oryzae isolates are shown

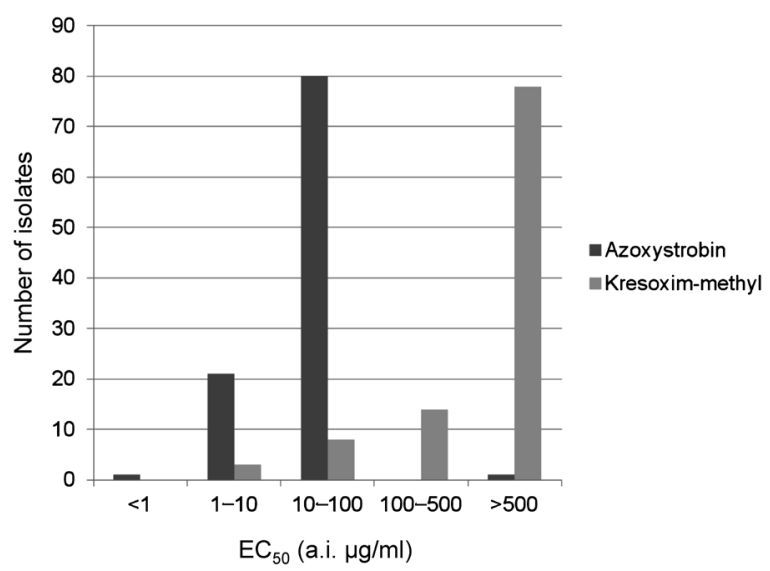

Fig. 4. The $50 \%$ effective concentration $\left(\mathrm{EC}_{50}\right)$ of azoxystrobin and kresoxim-methyl against isolates of Magnaporthe oryzae.

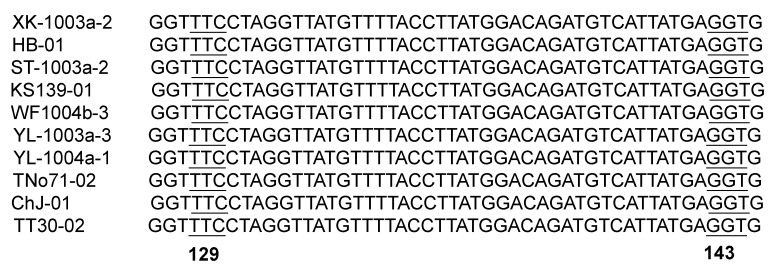

Fig. 5. The partial sequence of the cytochrome $b$ gene at codons 129 and 143 in Magnaporthe oryzae with different responses to azoxystrobin and kresoxim-methyl.

in Fig. 5. The $\mathrm{EC}_{50}$ values of kresoxim-methyl to YL-1004a-1, WF-1004b-3, ST-1003a-2, KS139-01, TNo71-02, TT30-02, XK1003a-2, YL-1003a-3, HB-01, and ChJ-01 were 483.39 \pm 7.18 , $3.05 \pm 2.58,1.65 \pm 0.49,>500,363.63 \pm 114.78,24.62 \pm 4.36$, $129.32 \pm 89.33,>500,>500$ and $>500 \mu \mathrm{g}$ a.i. $/ \mathrm{mL}$, respectively.

\section{Discussion}

All isolates of $M$. oryzae from different rice-production areas were separated into nine genetic groups based on CNS1 and $(\mathrm{CAG})_{5}$ primers. This study reveals for the first time the genetic diversity of $M$. oryzae in Taiwan. Many new rice cultivars have been planted in the field over the years. Among them some are tolerant or have intermediate resistance to M. oryzae. ${ }^{35)}$ The DNA polymorphism showed that the isolates of $M$. oryzae in groups A and B are dominant. The isolates in group A were widely distributed over the rice-production areas, and isolates in group B were distributed in most production areas except Tainan. Interestingly, the isolates of $M$. oryzae from the Chaiyi area showed high genetic diversity. According to the Agriculture and Food Agency, Chiayi is the main rice-producing region in Taiwan where many rice cultivars have been planted. Thus, the complexity of rice cultivars probably enriched the genetic polymorphism among M. oryzae isolates. Previous studies also indicated that the high diversity of pathogenicity or molecular lineage of $M$. oryzae could be induced by different rice cultivars. ${ }^{5-7,12)}$ Our results demonstrated that the isolates of $M$. ory$z a e$ from Chiayi were diversely associated with a number of rice cultivars, and the predominant groups were distributed over the 
rice production area.

The sensitivity of $M$. oryzae to various fungicides revealed that $M$. oryzae isolates from different rice-production areas in Taiwan have widely ranged sensitivity to these chemicals. MBIs are preferred fungicides for controlling rice blast in fields, and two types of MBIs, MBI-R (melanin biosynthesis inhibitorsreductase) and MBI-D (melanin biosynthesis inhibitors-dehydratase), showed different mechanisms for inhibiting plant fungal pathogens. ${ }^{23)}$ A previous study indicated that the tricyclazole-resistant isolate of $M$. oryzae had been screened under artificial conditions. ${ }^{28)}$ In this study, most of the MICAM values of tricyclazole were located between 0.1 and $0.4 \mu \mathrm{g}$ a.i. $/ \mathrm{mL}$, and the highest MICAM value was $0.8 \mu \mathrm{g}$ a.i. $/ \mathrm{mL}$. According to the guidelines issued by the Fungicide Resistance Action Committee, ${ }^{23)}$ the tricyclazole-resistant isolate of $M$. oryzae is still rarely detected in fields. Moreover, Zhang et al. (2005) also indicated that $1.0 \mu \mathrm{g}$ a.i./mL of MICAM is a demarcation line to identify the tricyclazole-resistant isolate of $M$. oryzae. ${ }^{38)}$ Thus, the $M$. oryzae isolates from Taiwan might be still sensitive to tricyclazole. On the other hand, the MICAM values of carpropamid against $M$. oryzae isolates were mostly located at $0.8 \mu \mathrm{g}$ a.i. $/ \mathrm{mL}$, with certain isolates at $2.0 \mu \mathrm{g}$ a.i./mL. Takagaki et al. (2004) demonstrated that 1 and $10 \mu \mathrm{g}$ a.i./mL of carpropamid did not have efficacy in control-resistant isolates of $M$. oryzae in the greenhouse. ${ }^{25)}$ Although several reports demonstrated that the carpropamid-resistant isolates of $M$. oryzae had been detected in fields, ${ }^{24,25,27,39)}$ the $M$. oryzae isolates from Taiwan still showed sensitivity to carpropamid. In addition, certain researchers indicated that using mycelial melanization also could be helpful to compare the sensitivity of $M$. oryzae isolates to tricyclazole ${ }^{28)}$ and carpropamid. ${ }^{24,40)}$ Zhang et al. (2006) used a minimum inhibition concentration of mycelial melanization (MIC-H) to detect the sensitivity of $M$. oryzae isolates from China to tricyclazole. ${ }^{28)}$ However, the MIC-H was considered not stable to examine the sensitivity of $M$. oryzae isolates to tricyclazole compared with MICAM. ${ }^{38)}$

Strobilurin fungicides, Quinone outside Inhibitors (QoIs), are commonly used to control fungal plant pathogens including oomycetes. ${ }^{23)}$ They inhibit mitochondrial ATP production in fungi. ${ }^{29)}$ However, many fungal pathogens have developed resistance to strobilurins in the field. ${ }^{23)}$ Although Magnaporthe spp. are high-risk fungal pathogens for fungicide resistance, few studies indicated that the strobilurin-resistant isolates were only detected in $M$. grisea in field samples. ${ }^{30,36)}$ In this study, the $\mathrm{EC}_{50}$ value of most $M$. oryzae isolates in Taiwan was greater than $500 \mu \mathrm{g}$ a.i./mL for kresoxim-methyl and less than 88.12 $4.46 \mu \mathrm{g}$ a.i./mL for an azoxystrobin fungicide. Thus, azoxystrobin seemed to be more efficient than kresoxim-methyl in the control of M. oryzae in Taiwan.

Molecular techniques have been established to diagnose the fungicide-resistant isolate of $M$. oryzae. For detection of strobilurin-resistant isolates, several reports indicated that the point mutation at codons 129 and 143 of the cyt $b$ gene is applicable. ${ }^{21,30)}$ However, isolates of $M$. oryzae in Taiwan did not show a point mutation at codon 129 or 143 of the cyt $b$ gene. Consequently, the mechanism of suspected low strobilurin sensitivity in isolates of $M$. oryzae was not caused by the known point mutations in the cyt $b$ gene. Previous studies indicated that alternative oxidase (AOX) is one way to decrease the damage of strobilurin fungicides in certain fungal pathogens. ${ }^{33,41,42)}$ Furthermore, the culture medium added with an AOX inhibitor of salicylhydroxamic acid (SHAM) or n-propyl gallate (PG) could increase the inhibitory activity of strobilurins against fungal pathogens. ${ }^{33,41,42)}$ In this study, the $M$. oryzae isolates showed variable sensitivity to azoxystrobin and kresoxim-methyl, and the different sensitivities might be caused by the level of AOX activity in each $M$. oryzae isolate. Moreover, another possible mechanism is the ATP-binding cassette (ABC) transports which transport the toxic material out the cell. $\mathrm{ABC}$ transports are also closely related to multiple drug resistances. ${ }^{21,42)}$ Thus, the AOX and $\mathrm{ABC}$ transports might play an important role in reducing the damage of strobilurin fungicides in the less sensitive M. ory$z a e$ isolates from Taiwan. It warrants further investigation to confirm the mechanism of the resistance to strobilurins.

Results of the comparison of the relationship between fungicide sensitivity and different genetic groups showed that the response to QoIs did not correspond with DNA polymorphism of $M$. oryzae. Isolates of $M$. oryzae in group A or B showed different sensitivity to MBIs and strobilurins. Moreover, isolates of M. oryzae in non-dominant groups did not show a different response to MBIs or strobilurins. Thus, the polymorphism of DNA has no correlation to the response of $M$. oryzae to strobilurins. Previous studies also indicated that the molecular polymorphism of M. oryzae is not associated with its pathogenicity. ${ }^{16,43)}$

\section{Acknowledgements}

We sincerely thank Dr. C. J. Chang, Plant Pathologist, Department of Plant Pathology, University of Georgia, Griffin, GA, USA, for his critical reading of the manuscript. Funding to support this research was provided by NSC99-2313-B-005-015-MY3 from National Science and Technology Program for Agricultural Biotechnology, National Science Council, Taiwan, ROC, and in part by the Ministry of Education, Taiwan, ROC, under the ATU plan.

\section{References}

1) B. Valent and F. G. Chumley: Annu. Rev. Phytopathol. 29, 443-467 (1991).

2) N. J. Talbot: Annu. Rev. Microbiol. 57, 177-202 (2003).

3) H. Asuyama: "Morphology, Taxonomy, Host Range, and Life Cycle of Pyricularia oryzae," ed. by R. F. Jr. Chandler, Johns Hopkins Press, USA, pp. 9-22, 1965.

4) S. H. Ou: Annu. Rev. Phytopathol. 18, 167-187 (1980).

5) V. F. Consolo, C. A. Cordo and G. L. Salerno: Australas. Plant Pathol. 37, 357-364 (2008).

6) G. B. da Silva and L. G. de Araújo V. L. da Silva lobo, A. S. Prabhu, M. C. F. Rêgo, E. T. Paes and M. C. C. de Filippi: Bragantia Campinas 70, 860-868 (2011).

7) J. J. D. Neto, G. R. dos Santos, L. M. dos Anjos, P. H. N. Rangel and M. E. Ferreira: Pesq. Agropec. Bras. Brasilia 45, 252-260 (2010).

8) A. S. Prabhu, L. G. Araújo, G. B. Silva and M. G. Trindade: Fitopatol. 
Bras. 32, 13-20 (2007).

9) H. L. Chen, B. T. Chen, D. P. Zhang, Y. F. Xie and Q. Zhang: Plant Dis. 85, 843-850 (2001).

10) J. Q. Xia, J. C. Correll, F. N. Lee, M. A. Marchetti and D. D. Rhoads: Phytopathology 83, 1029-1035 (1993).

11) P. Mekwatanakarn, W. Kositratana, M. Levy and R. S. Zeigler: Plant Dis. 84, 60-70 (2000).

12) N. T. N. Thuan, J. Bigirimana, E. Roumen, D. Van Der Straeten and M. Höfte: Eur. Plant Pathol. 114, 381-396 (2006).

13) C. C. Chien: Sp. Issue Agr. Res. 30, 63-74 (1990).

14) R. S. Chen: "Proceedings of Symposium on Achievements and Perspectives of Rice Protection in Taiwan," ed. by H. F. Ni and H. R. Yang, Special Publication of TARI No. 138, Taichung, Taiwan, pp. 149-160, 2009.

15) K. A. Abd-Elsalam, J. R. Guo, M. A. Moslem, A. H. Bahkali and J. A. Verreet: J. Rapid Meth. Aut. Mic. 17, 383-397 (2009).

16) R. S. Zeigler, L. X. Cuoc, R. P. Scott, M. A. Bernardo, D. H. Chen, B. Valent and R. J. Nelson: Phytopathology 85, 443-451 (1995).

17) M. L. Farman, Y. Tosa, N. Nitta and S. A. Leong: Mol. Gen. Genet. 251, 665-674 (1996).

18) L. D. Don, M. Kusaba, A. S. Urashima, Y. Tosa, H. Nakayashiki and S. Mayama: Ann. Phytopathological Soc. Jpn. 65, 15-24 (1999).

19) P. Kachroo, S. A. Leong and B. B. Chattoo: Mol. Gen. Genet. 245, 339-348 (1994).

20) H. Adreit, Santoso, D. Andriantsimialona, D. W. Utami, J. L. Notteghem, M. H. Lebrun and D. Tharreau: Mol. Ecol. Notes 7, 667-670 (2007).

21) Y. Araki, M. Sugihara, H. Sawada, H. Fujimoto and M. Masuko: Pestic. Sci. 3, 203-208 (2005).

22) W. C. Fei, Y. M. Wang, F. C. Chen, C. M. Lin and Y. H. Lee: "Plant Protection Manual," Taiwan Agriculture Chemicals and Toxic Substances Research Institute, Wufeng, Taichung, Taiwan, 2010.

23) Fungicide Resistance Action Committee: "List of Plant Pathogenic Organisms Resistant To Disease Control Agents," The Fungicide Resistance Action Committee, Brussels, Belgium, 2010.

24) H. Sawada, M. Sugihara, M. Takagaki and K. Nagayama: Pest Manag. Sci. 60, 777-785 (2004).

25) M. Takagaki, K. Kaku, S. Watanabe, K. Kawai, T. Shimizu, H. Sawada,
K. Kumakura and K. Nagayama: Pest Manag. Sci. 60, 921-926 (2004).

26) N. Yamada, T. Motoyama, M. Nakasako, S. Kagabu, T. Kudo and I. Yamaguchi: Biosci. Biotechnol. Biochem. 68, 615-621 (2004).

27) J. Yamaguchi, F. Kuchiki, K. Hirayae and K. So: Jpn. J. Phytopathol. 68, 261 (2002) (abstract in Japanese).

28) C. Q. Zhang, G. N. Zhu, Z. H. Ma and M. G. Zhou: J. Phytopathol. 154, 392-397 (2006).

29) D. W. Bartlett, J. M. Clough, J. R. Godwin, A. A. Hall, M. Hamer and B. Parr-Dobrzanski: Pest Manag. Sci. 58, 649-662 (2002).

30) P. Vincelli and E. Dixon: Plant Dis. 86, 235-240 (2002).

31) L. S. Chen, W. C. Chung and W. H. Chung: J. Agr. Forest. 59, 231-252 (2010).

32) M. T. Peng: Master Thesis, National Chung Hsing University, Taichung, Taiwan, 2008 (in Chinese with English Abstract).

33) V. Grasso, S. Palermo, H. Sierotzki, A. Garibaldi and U. Gisi: Pest Manag. Sci. 62, 465-472 (2006).

34) Y. S. Kim, E. W. Dixon, P. Vincelli and M. L. Farman: Phytopathology 93, 891-900 (2003).

35) Y. C. Chang: "Manual control of rice blast," Taiwan Agricultural Research Institute, Taichung, Taiwan, 2001.

36) J. Sambrook and D. W. Russell: "Molecular Cloning, A Laboratory Manual, 3rd Ed.," ed. by J. Sambrook and D. W. Russell, Cold Spring Harbor Laboratory Press, New York, NY, USA, pp. 6.1-6.64, 2001.

37) T. Eizuka, T. Sato, T. Chida and I. Yamaguchi: J. Pestic. Sci. 26, 385389 (2001).

38) C. Q. Zhang, M. G. Zhou and X. Na: Chin. J. Rice Sci. 19, 79-84 (2005).

39) F. Suzuki, M. Arai and J. Yamaguchi: Plant Dis. 91, 176-184 (2007).

40) Y. Kurahashi, Y. Araki, T. Kinbara, R. Pontzen and I. Yamaguchi: J. Pestic. Sci. 23, 22-28 (1998).

41) L. S. Chen, W. C. Chung and W. H. Chung: Plant Pathol. Bull. 18, 89-99 (2009).

42) H. Ishii, J. Fountaine, W. H. Chung, M. Kansako, K. Nishimura, K. Takahashi and M. Oshima: Pest Manag. Sci. 65, 916-922 (2009).

43) F. Correa-Victoria, M. Levy and R. Zeigler: "Proceedings of the International Symposium of Rice Blast Disease," ed. by S. A. Leong, R. S. Zeigler and P. S. Teng, CAB International, Wallingford, UK, pp. 211-230, 1994. 